\title{
Variation in Circulating Testosterone during Mating Predicts Reproductive Success in a Wild Songbird
}

\author{
Beate Apfelbeck ${ }^{1,2,3 *}$, Heiner Flinks ${ }^{4}$ and Wolfgang Goymann ${ }^{1}$ \\ ${ }^{1}$ Abteilung für Verhaltensneurobiologie, Max-Planck-Institut für Ornithologie, Seewiesen, Germany, ${ }^{2}$ Institute of Biodiversity, \\ Animal Health and Comparative Medicine, University of Glasgow, Glasgow, Scotland, UK, ${ }^{3}$ Terrestrial Ecology Research \\ Group, Department of Ecology and Ecosystem Management, School of Life Sciences Weihenstephan, Technische \\ Universität München, Freising, Germany, ${ }^{4}$ Independent Researcher, Borken, Germany
}

\section{OPEN ACCESS}

Edited by:

Carlos Alonso Alvarez, Spanish National Research Council,

Reviewed by:

Tessa K. Solomon-Lane,

University of Texas at Austin, USA

Nicole M. Gerlach,

University of Florida, USA

*Correspondence:

Beate Apfelbeck bea.apfelbeck@gmx.de

Specialty section:

This article was submitted to Behavioral and Evolutionary Ecology,

a section of the journal

Frontiers in Ecology and Evolution

Received: 23 May 2016 Accepted: 18 August 2016 Published: 31 August 2016

Citation: Apfelbeck B, Flinks H and Goymann W (2016) Variation in Circulating

Testosterone during Mating Predicts Reproductive Success in a Wild Songbird. Front. Ecol. Evol. 4:107. doi: 10.3389/fevo.2016.00107
Testosterone is an important sex hormone and mediates reproduction in male vertebrates. There is ample evidence that testosterone coordinates the expression of physiological, morphological, and behavioral traits during reproduction and many of these traits are under sexual selection. However, only few studies so far have examined if individual variation in testosterone is correlated with reproductive success. Because socially monogamous bird species pass through different phases within a breeding cycle and each of these phases requires the expression of different behaviors, the relation between testosterone and reproductive success could vary with breeding stage. Here we investigate the link between reproductive success and testosterone in European stonechats - a socially monogamous songbird with biparental care. Previous studies found that territorial aggression in breeding stonechats depends on testosterone and that testosterone levels peak during the mating phase. Thus, high testosterone levels during mating may influence reproductive success by promoting territorial aggression and mate guarding. We found that males with two breeding attempts produced a similar number of fledglings as males with three breeding attempts. However, males with two breeding attempts expressed higher levels of testosterone than males with just one or those with three breeding attempts, regardless of whether testosterone was measured during the mating or the parental phase of the first brood. Furthermore, testosterone levels during mating, but not during parenting, correlated with the total annual number of fledglings. Thus, individual variation in levels of plasma testosterone predicted reproductive success in stonechats.

\section{Keywords: androgens, individual variation, number of fledglings, number of clutches, fitness}

\section{INTRODUCTION}

Reproduction in male vertebrates is mediated by androgens which activate spermatogenesis and facilitate the expression of secondary sex characteristics and reproductive behaviors (AdkinsRegan, 2005; Nelson, 2005). The androgen testosterone enhances mating effort by mediating reproductive behaviors, such as courtship (e.g., Fusani, 2008), copulation (e.g., Balthazart et al., 1995), song (e.g., Ball et al., 2002), and territorial aggression (e.g., Wingfield, 2005), as well as sexually selected morphological traits in many bird species (Adkins-Regan, 2005; Nelson, 2005). However, prolonged periods with elevated levels of testosterone can incur costs and may decrease survival (Wingfield et al., 2001) because males with high levels of testosterone tend to invest less into 
self-maintenance and immune function (Malo et al., 2009), can be more conspicuous to predators (Marler and Moore, 1988), and are prone to get injured during fights (Marler and Moore, 1989). Experimental studies have shown that testosterone can shift the balance between reproduction and survival toward reproduction (Ketterson et al., 1992; Reed et al., 2006; Mills et al., 2009). Further, high levels of testosterone can interfere with male parental care. Hence, males of many socially monogamous species with biparental care show a peak in testosterone during the mating phase and a decline of testosterone during the parental phase (e.g., Wingfield and Hahn, 1994; Schwabl et al., 2005; Apfelbeck et al., 2013). When testosterone concentrations are experimentally enhanced during the parental phase, males of some species reduce nestling provisioning behavior (Silverin, 1980; Hunt et al., 1999; Schwagmeyer et al., 2005). In contrast, in polygynous species without paternal care, males invest mostly into mating and as a consequence testosterone levels tend to be elevated throughout the breeding season (e.g., Beletsky et al., 1992). Therefore, depending on the social mating system, the species-specific life history, and the balance between mating effort, survival and parental care, the role of testosterone can differ between species.

The above mentioned correlational and experimental evidence suggests a causal relationship between testosterone and reproductive behaviors, and a mechanistic role for testosterone in the resolution of life history trade-offs. However, we know little about the adaptive consequences of natural variation in testosterone levels between individuals of the same species. Through testosterone's positive effect on behaviors associated with mating effort and sexually selected morphological traits, individual variation in circulating testosterone concentrations during mating should predict reproductive success of individuals. Indeed, in lekking and polygynous species without paternal care, mating success correlates positively with testosterone in all species studied to date (Borgia and Wingfield, 1991; Beletsky et al., 1992; Alatalo et al., 1996; Vitousek et al., 2008; Smith et al., 2015). In socially monogamous and biparental species, only a single study found a relationship between circulating $\mathrm{GnRH}$-induced testosterone levels and reproductive success. In contrast to the studies on polygynous species, selection on testosterone levels in dark-eyed juncos (Junco hyemalis) was stabilizing: males with slightly higher than average testosterone concentrations had the highest reproductive success and were most likely to survive (McGlothlin et al., 2010). On the other hand, in a study on North-American barn swallows (Hirundo rustica erythrogaster) no relationship between testosterone levels and total number of offspring was found (Eikenaar et al., 2011). In polygynous and especially in lekking species testosterone probably directly affects male reproductive success via its positive effect on display activity and aggressiveness throughout the breeding season (Borgia and Wingfield, 1991; Alatalo et al., 1996; Vitousek et al., 2008). Reproductive success in polygynous and lekking species depends mostly on mating success (number of copulations with different females) and females choose males on the basis of ornaments, displays, and fighting ability (Höglund and Alatalo, 2014). In socially monogamous species, the reproductive success of males depends on various factors, and different traits and endocrine control mechanisms may act during different phases of the breeding cycle (Jacobs and Wingfield, 2000). For example, migratory male songbirds need to establish a territory and attract a mate at the beginning of the breeding season. Thus, the reproductive success of a male will depend on his ability to maintain a high quality territory and to find a suitable mate. During the fertile period of the female, the reproductive success of a male will depend on how well he is able to guard and defend his mate against competing males that seek extra-pair copulations. Later in the season, the parental qualities of a male may become more important. There is good evidence that in socially monogamous, biparental species, testosterone may influence reproductive success through its effect on male performance during territory establishment and/or mate guarding (Wingfield et al., 1990, 2006). After the mating phase of the first brood, however, males have to balance their investment into mating (including extra-pair behavior), and parental care. For example, in dark-eyed juncos individual variation in $\mathrm{GnRH}$-induced testosterone concentrations correlated positively with territorial aggression, but negatively with offspring care (McGlothlin et al., 2007), and experimentally elevated testosterone levels impaired paternal care (Ketterson et al., 1992). In the above cited study on dark-eyed juncos, testosterone concentrations of males caught during mating and parental phases were combined to a single value for each individual (McGlothlin et al., 2010). However, because males of socially monogamous species care for young, covariation of testosterone levels with reproductive success may vary with breeding stage: high testosterone levels may be favored during mating, but low levels may be favored during parenting (Wingfield et al., 1990).

Furthermore, because in socially monogamous species reproductive success depends on different traits during different breeding phases within a breeding cycle, mating success cannot be equated as easily with reproductive success as in polygynous species. It is, therefore, necessary to use a direct measure of reproductive success. In some species the number of breeding attempts directly predicts the number of fledglings, with more breeding attempts typically resulting in more fledglings (Weggler, 2006). But in ground-nesting species with a high probability of nest failure due to predation this is not necessarily true. Hence, different approximations of reproductive success may vary in the strength of their covariation with testosterone. Thus, the relationship between individual variation in testosterone levels and reproductive success may differ between species and breeding stages depending on the extent of the trade-off between mating effort and parental care (Ketterson and Nolan, 1992). Especially in socially monogamous species with biparental care the role of testosterone may depend strongly on breeding stage.

For this reason, we related the individual variation in circulating testosterone to reproductive success separately during the mating and the parental phase in a wild population of the European stonechat (Saxicola torquatus), a socially monogamous songbird with biparental care. We measured reproductive success indirectly as the number of breeding attempts of a pair, and directly as the total annual number of fledged young per breeding season.

European stonechats are short distance migrants, they raise up to three (occasionally four) broods per breeding season, 
and both partners take care of the young (Urquhart, 2002). After arriving on their breeding grounds, male stonechats establish territories, and advertise for females via singing from elevated song posts, in general the top of a tree or bush. Song is under sexual selection (Mortega et al., 2014) and may communicate a males' quality in a reproductive context (GreigSmith, 1982). Especially during nest-building-the fertile period of the female (Birkhead and Møller, 1993) - males stay close to their partners. Only the female builds the nest and incubates; however, most males stay in the vicinity of the nest and act as sentinels (Urquhart, 2002). The fledgling phase and nest initiation of consecutive broods overlap (Flinks and Pfeifer, 1987). Testosterone concentrations and aggressive behavior of male stonechats peak during the mating phase of the first brood (Schwabl et al., 2005; Apfelbeck et al., under review) and male mating effort-measured as territorial aggression-depends on testosterone during the breeding, but not during the nonbreeding season (Canoine and Gwinner, 2002; Marasco et al., 2011). Furthermore, males with high testosterone concentrations are more likely to attack a territorial intruder during the mating phase than males with low testosterone concentrations (Apfelbeck et al., under review). Thus, testosterone in stonechats seems to facilitate high intensity aggression during mating, and may thereby promote within-pair reproductive success of males by preventing extra-pair-copulations during the fertile period of the female partner. This may be especially relevant when the first clutch of the season is laid, because nest initiation is more synchronous during the first than during consecutive broods (Flinks and Pfeifer, 1987). Also, because stonechats overlap consecutive broods, mating and parental stages overlap after the first brood has been initiated and thus, potential benefits of high testosterone levels during the mating phases of later broods may be outweighed by the negative effects on parental behavior. In line with this expectation, testosterone levels of male stonechats decrease after the mating phase of the first brood (Schwabl et al., 2005; Apfelbeck et al., under review). Hence, assuming a tradeoff between mating and parenting (Wingfield et al., 1990), we predicted that reproductive success in male stonechats should be related to high levels of testosterone during the mating phase of the first brood, and low testosterone levels during the parenting phase of the first brood. Furthermore, because nest predation in stonechats is high, we predicted that testosterone concentrations during the mating phase should be related to the total annual number of fledglings, but not so much to the total number of breeding attempts.

\section{METHODS}

We assessed testosterone levels and reproductive success of male stonechats breeding in Germany at two study sites that were $60 \mathrm{~km}$ apart: the Düffel $\left(20 \mathrm{~km}^{2}, 51^{\circ} 47^{\prime} \mathrm{N}, 6^{\circ} 01^{\prime} \mathrm{E}\right)$ and the Heubach lowland $\left(6 \mathrm{~km}^{2}, 51^{\circ} 84^{\prime} \mathrm{N}, 7^{\circ} 08^{\prime} \mathrm{E}\right)$. From 2009 to 2013 we caught 143 males as part of a study on the effect of territorial aggression on testosterone levels. Of these 143 males we were able to collect information on annual reproductive success from 73 males. All experimental procedures were approved by the governmental authorities of North Rhine Westphalia.
Males were caught passively with baited spring traps, or actively with spring traps and a mounted decoy and playback between 7:00 and 18:00 $\mathrm{h}$ during the mating phase (pre-nesting and nest-building) of the first brood and during the parental phase (incubation, nestlings, fledglings) of the first brood and occasionally of the second brood $(n=13)$. Each male was caught only once. Briefly, actively caught birds were lured with a remotecontrolled loudspeaker (Foxpro Scorpion, digital game caller, FOXPRO Inc. Lewistown, USA) that was put underneath a decoy and song was played back. In stonechats, such a stimulation with a decoy and playback does not change circulating testosterone concentrations (Apfelbeck et al., under review), and hence the data from passively and actively caught birds were combined.

To assess breeding stage and reproductive success, all breeding territories of the population were checked at least once every week from February until September. Breeding stage was determined through careful observation of pairs before capture (e.g., song, nest-building by females, feeding of nestlings, and presence of fledglings). In some cases, we were able to catch the female and breeding stage could be ascertained by noting the presence or absence of a brood patch. Females incubate clutches for $\sim 14$ days and nestlings stay in the nest for another 16 days (Koenig and Gwinner, 1995). We attempted to record all breeding attempts (i.e., the total number of all clutchesincluding successful, failed, and replacement clutches) and the total annual number of young that successfully fledged. Because stonechats nest on the ground and hide their nests below tufts of grass, it is not always easy to find their nests. Therefore, for some individuals we only have a full record of the number of breeding attempts, and for others we were able to record the total number of fledglings-leading to differences in samples sizes.

\section{Hormone Analysis}

Upon capture $(312 \pm 195 \mathrm{~s})$, a blood sample $(\sim 120 \mu \mathrm{l})$ was taken from the wing vein and the plasma was immediately separated by centrifugation with a Compur Minicentrifuge (Bayer Diagnostics). The amount of plasma was measured with a Hamilton syringe and stored in $500 \mu \mathrm{l}$ pure ethanol (Goymann et al., 2007). Testosterone concentration was determined by direct radioimmunoassay (RIA, following Goymann et al., 2006; Apfelbeck and Goymann, 2011). Mean efficiency of the extraction with dichloromethane varied between 85 and $88 \%$. The lower limit of detection of the assay was on average $0.35 \pm 0.05 \mathrm{pg} /$ tube. Samples were measured in duplicates in 5 assays. The intraextraction coefficients of variation ranged between 2.8 and $11.8 \%$ (mean 5.6\%). The inter-assay variation was $11.9 \%$.

\section{Statistical Analysis}

Data were analyzed within the $\mathrm{R}$ environment ( $\mathrm{R}$ version 3.2.2, R Core Team, 2016) and the packages JAGS (Plummer, 2003) and runjags (Denwood, 2016). We used general linear models to determine if variation in testosterone concentrations was related to reproductive success in stonechats. To draw inferences from the models we chose a Bayesian approach and estimated the model parameters as the mean of their posterior distributions, and the 2.5 and $97.5 \%$ credible intervals. We used minimally informative priors for both mean $\left[\operatorname{dnorm}\left(0,10^{\wedge-6}\right)\right]$ and precision [dgamma $(0.001,0.001)]$ parameters, i.e., for mean 
parameters the prior distribution was flat over a wide range of values and precision parameters were shrunk toward zero (Mair et al., 2015). Post-capture testosterone concentrations were natural log-transformed and predictor covariates (body mass, time of day, number of fledglings) were centered to a mean of zero.

We tested if reproductive success (number of breeding attempts: $n=68$, number of fledglings: $n=64$ ) explained variation in post-capture testosterone levels and if this relationship differed between breeding stages. We differentiated mating (pre-nesting and nest-building of the first brood) from parenting (incubation, nestlings, and fledglings) and ran all analyses twice: once including also individuals that were caught during the parental phase of their second brood and once restricted to individuals that were caught only during their first brood. We further tested if the number of breeding attempts was predictive of the total annual number of fledglings using a quasi-poisson generalized linear model. In this last analysis also data from males without information on testosterone were included $(n=118)$.

MCMC simulations were checked for convergence of chains using trace plots and psrf values (Brooks and Gelman, 1997). Effective sample sizes for the simulation were $>15000$ in all cases. Model residuals were graphically checked for violations of model assumptions (normality, heteroscedasticity, auto-correlations). Hormone estimates are reported on a natural log scale unless stated otherwise. Data are presented as means and their 95\% credible intervals (in squared brackets). Bayesian statistics do not produce test statistics or $p$-values, however, if the $95 \%$ credible interval of the difference between two means includes zero, there is no biologically meaningful difference.

\section{RESULTS}

Males with two breeding attempts expressed higher post-capture testosterone levels than males with one or three breeding attempts, independent of breeding stage [all data $=$ individuals caught during 1 st and 2 nd breeding attempt: $F_{(5,62)}=9.4$, $R^{2}=0.39$, reduced data $=$ individuals caught during first breeding attempt only: $F_{(5,49)}=7.9, R^{2}=0.39$, Figure 1]. Further, the total annual number of fledglings was positively related to circulating post-capture testosterone concentrations during the mating phase (Figure 2A). Such a relationship was absent when testosterone was measured during the parental phase [all data: $F_{(3,60)}=8.7, R^{2}=0.27$, reduced data: $F_{(3,47)}=$ $7.4, R^{2}=0.27$, Figure $\left.2 \mathrm{~B}\right]$. During the mating phase males expressed higher concentrations of post-capture testosterone than during the parental phase (Figure 1). Males with two or three breeding attempts produced almost twice as many fledglings than males with only one breeding attempt (residual deviance: 288 , df $=115$, dispersion parameter: 1.9, Table 1). However, males with three breeding attempts did not produce more fledglings than males with only two breeding attempts, because third clutches were mainly the result of a replacement clutch for lost second broods (Table 1).
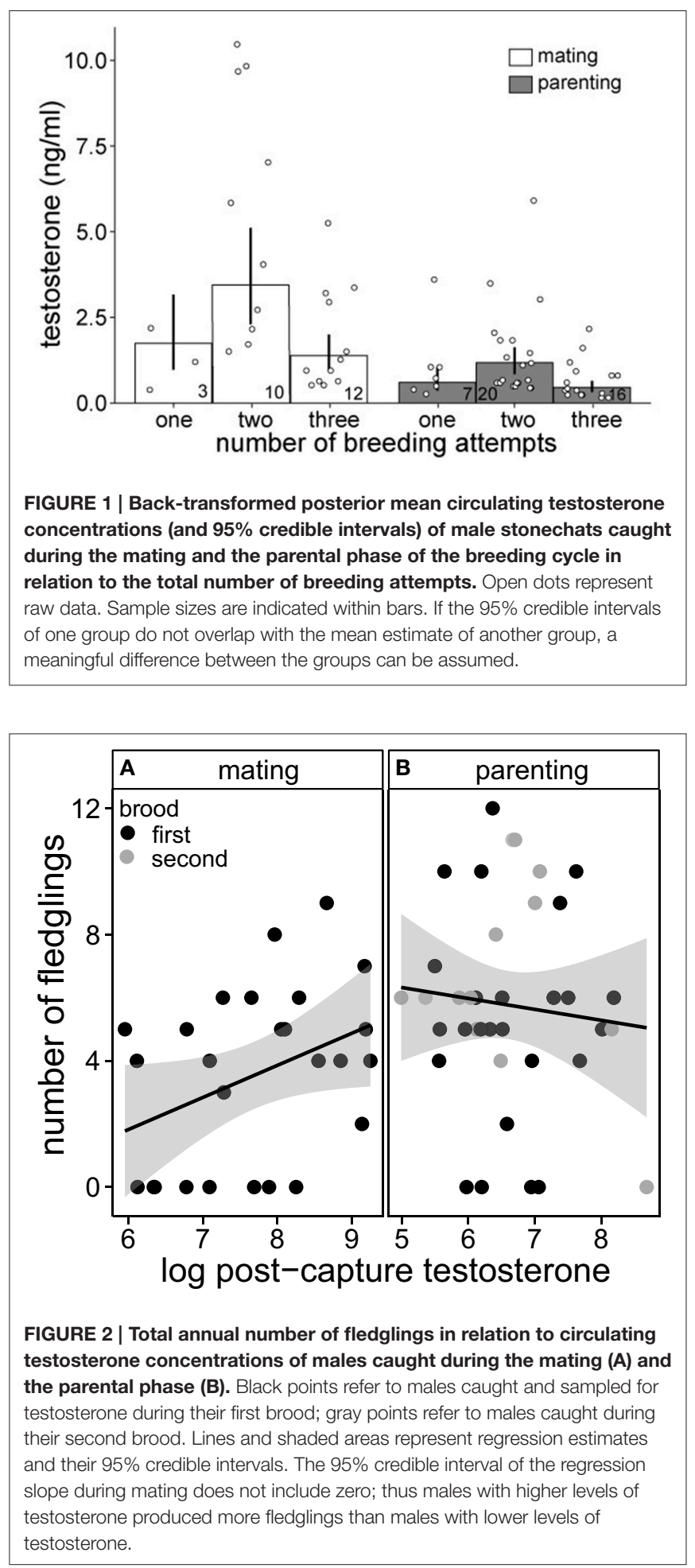

\section{DISCUSSION}

In accordance with testosterone's role as a mediator of male mating effort, stonechats with higher levels of testosterone during the mating phase of the first brood experienced a higher annual reproductive success-measured as the total annual number 
TABLE 1 | Breeding attempts and reproductive success.

\begin{tabular}{|c|c|c|c|c|c|}
\hline $\begin{array}{l}\text { Number of breeding } \\
\text { attempts }\end{array}$ & $\begin{array}{l}\text { Estimates and } 95 \% \text { credible } \\
\text { intervals }\end{array}$ & $\begin{array}{l}\text { Average number of } \\
\text { fledglings }\end{array}$ & $\begin{array}{l}\text { One clutch } \\
\text { failed }\end{array}$ & $\begin{array}{l}\text { Two clutches } \\
\text { failed }\end{array}$ & $\begin{array}{c}\text { Three clutches } \\
\text { failed }\end{array}$ \\
\hline $1(n=15)$ & $2.9[1.9,4.4]$ & 2.9 & $6(40 \%)$ & - & - \\
\hline $2(n=53)$ & $5.1[3.3,7.7]$ & 6.25 & $21(40 \%)$ & $8(15 \%)$ & - \\
\hline $3(n=65)$ & $5.3[3.5,7.9]$ & 7.0 & 24 (37\%) & 26 (40\%) & 6 (9\%) \\
\hline
\end{tabular}

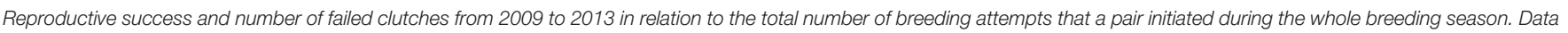

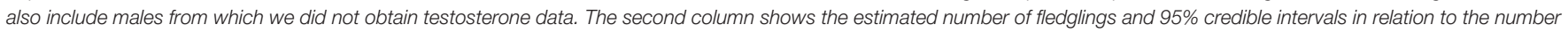

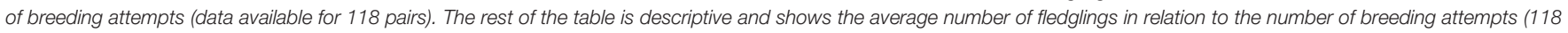

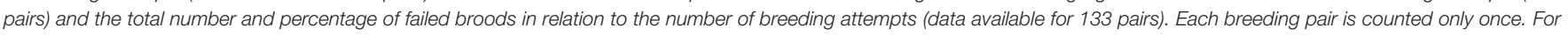
example, in 6 out of the 15 breeding pairs that had only one breeding attempt during the whole breeding season this brood failed.

of successfully fledged young-than males with lower levels of testosterone. However, although testosterone was generally lower during the parental phase, there was no relationship between testosterone and the number of fledglings during this period. Furthermore, males with two breeding attempts expressed higher levels of testosterone than males with one or three breeding attempts, independent of breeding stage. Thus, while the relationship between the total number of fledglings and testosterone during mating was positive and linear, it was non-linear with respect to the number of breeding attempts.

Because stonechats are ground nesting birds, nest predation is high in this population (Flinks and Pfeifer, 1987). Accordingly, we found that more breeding attempts reflected a higher number of fledglings only to a certain degree: pairs with only one breeding attempt produced the lowest number of fledglings; but, pairs with three breeding attempts did not produce more fledglings than pairs with two breeding attempts. Indeed, third broods often represented replacement clutches of failed second broods.

Males with two breeding attempts and high testosterone levels during the mating phase may be high-quality males that have been chosen by more experienced or high-quality females and together they may be more successful in raising a clutch (Baran and Adkins-Regan, 2014). High quality may be signaled to females through testosterone-mediated ornaments (Yang et al., 2013) or behavioral traits such as defense of a high-quality territory (Vitousek et al., 2008). High testosterone levels have been shown to increase mating effort via territorial aggression, courtship displays, and mate-guarding behavior. Stonechats are highly territorial and testosterone facilitates territorial behavior in this species (Canoine and Gwinner, 2002; Marasco et al., 2011). Furthermore, they show intensive mateguarding behavior (Urquhart, 2002) especially during the period when females are fertile and when testosterone concentrations of males peak (Schwabl et al., 2005). Thus, testosterone may promote reproductive success of males via successful territorial defense and effective mate guarding and prevention of extra pair copulations.

Testosterone concentrations of males caught during the parental phase did not correlate with the total number of fledglings, but the relationship of testosterone with the number of breeding attempts mirrored the one found during the mating phase, i.e., males with two breeding attempts expressed higher testosterone levels than males with one or three breeding attempts also when caught during parenting. Thus, although testosterone levels decreased during parenting, higher than average levels of testosterone may still promote a higher reproductive success. For example, testosterone may increase vigilance behavior-a behavior that is sexually selected and decreases predation risk (Fusani et al., 1997). Male stonechats function as sentinels for nest-building and incubating females (Urquhart, 2002). Thus, high testosterone levels may also facilitate sentinel behavior and thereby reduce the risk of predation and nest failure. Through its effect on vigilance behavior, higher than average levels of testosterone may be advantageous also during the parental phase. Furthermore, even though testosterone implants typically suppress paternal care in birds (e.g., Silverin, 1980; Hegner and Wingfield, 1987; Ketterson et al., 1992; Schwagmeyer et al., 2005), males of some species do not alter their provisioning behavior when they receive a testosterone implant (Van Duyse et al., 2000; Lynn et al., 2002). In such species, nestling provisioning by the male is considered to be essential for the success of the brood and down-regulation of androgen receptors in the brain may prevent any effects of testosterone on male behavior during the nestling stage (Lynn, 2016). Typically, male parental care is essential in species with extremely short breeding seasons and harsh breeding environments that allow only for one brood to be raised, such as in the Arctic (Lynn et al., 2005). European stonechats are multiple-brooded and male parental care is not essential: occasionally, adult stonechats are predated and both males and females seem to be able to then raise the brood successfully without their partner (H.F., personal observations).

Slightly elevated testosterone levels during parenting may be advantageous for another reason. Most songbirds are monogamous only on a social basis, but extra-pair paternity is quite common. Stonechats are no exception (Villavicencio et al., unpublished data). Especially when their own mate is incubating, males may try to increase their reproductive success through extra-pair matings with neighboring or other females. For example, testosterone did not affect space usage of male darkeyed juncos during the fertile period of their mates (Chandler et al., 1997), but it did induce males to venture further away from their nests while their mate was incubating (Chandler et al., 1994). Further, experimental studies in dark-eyed juncos indicated that testosterone implanted males increased their reproductive success because they had more extra-pair matings (Raouf et al., 1997; Reed et al., 2006). In contrast, in superb fairywrens (Malurus cyaneus), experimentally elevated testosterone 
levels increased within-pair courtship displays, but did not affect the frequency of extra-pair matings (Peters, 2002). In a correlational study on Seychelles warblers (Acrocephalus sechellensis), peak testosterone concentrations coincided with within-pair copulation displays and mate-guarding, but not with extra-pair mating opportunities (Van de Crommenacker et al., 2004). Thus, it is likely that natural variation in testosterone relates differently to within and extra-pair reproductive success depending on the species studied. In their study on darkeyed juncos, McGlothlin et al. found that after partitioning reproductive success into within- and extra-pair reproductive success, selection on testosterone was directional and positive with respect to within-pair reproductive success, but it was stabilizing with respect to extra-pair mating success (McGlothlin et al., 2010). In contrast, in North-American barn swallows, testosterone levels during mating neither correlated with withinnor with extra-pair mating success (Eikenaar et al., 2011). However, although North-American barn swallows are socially monogamous, extra pair paternity rates are extremely high in this species (42\%, Eikenaar et al., 2011). In contrast to darkeyed juncos and stonechats, barn swallows are colonial and breed in sheltered barns. Furthermore, although darker-colored, more aggressive males have higher testosterone levels and are less often cuckolded (Safran et al., 2008; Eikenaar et al., 2011), darker-colored aggressive males may have to bear high energetic costs resulting in a low body condition (Safran et al., 2008). This may negate an overall positive effect of testosterone on reproductive success. We suggest that in stonechats the main role of testosterone is to prevent the female partner from seeking extra-pair copulations by promoting territorial aggression and mate guarding during the fertile period of the female-especially during the first brood, when competition is likely to be highest. Testosterone may, therefore, enhance male reproductive success mainly through within-pair mating success and only to a lesser degree through extra-pair paternity. Similar to the present study on stonechats, a study in black redstarts (Phoenicurus ochruros) found that males that performed better had higher levels of testosterone during parenting than males that were less successful: male black redstarts that lost paternity had lower levels of testosterone, but higher levels of corticosterone, during parenting than males that did not lose paternity (Villavicencio et al., 2014). This supports our hypothesis in stonechats that males with high testosterone levels may be males that are more effective in mate-guarding and in better condition. Although male parental care may not be essential, within-pair mating success may still be substantially increased by the presence of the male and its role as a nest sentinel, in particular when predator numbers are high (Greig-Smith, 1980; Scheuerlein et al., 2001). We were not able to differentiate between within- and extra-pair young during this study. However, we expect that testosterone should correlate stronger with within-pair number of fledglings than with extra-pair young or the total apparent number of young per nest.

Circulating testosterone levels can be highly labile, varying, for example, over the course of the day or with social interactions (Wingfield et al., 1990). It has, therefore, been suggested that maximum testosterone levels induced through gonadotropin-releasing hormone $(\mathrm{GnRH})$ injections represent a more reliable estimate of individual testosterone concentrations than post-capture testosterone concentrations (McGlothlin et al., 2010). Indeed, in the studies on dark-eyed juncos, reproductive success, aggressive, and paternal behavior were associated with the GnRH-induced increase in testosterone concentrations, rather than with post-capture levels of testosterone (McGlothlin et al., 2007, 2010). In stonechats, GnRH-induced testosterone levels were positively correlated with post-capture testosterone concentrations during the mating phase (Apfelbeck et al., under review). This indicates that post-capture testosterone may represent a reliable estimate of the capacity of individuals to produce testosterone during the mating phase (see Goymann et al., 2015 for similar results in black redstarts). However, to fully understand how testosterone may influence reproductive success through its effects on reproductive behaviors, we need to understand the action of androgens in the brain. Especially we need more profound knowledge of how individual variation in hormone levels relates to individual variation of cellular and molecular measures (e.g., hormone receptors) in respective target tissues (Ball and Balthazart, 2008; Rosvall et al., 2012).

\section{CONCLUSIONS}

There is ample evidence that testosterone coordinates the expression of physiological, morphological, and behavioral traits during reproduction and many of these traits are under sexual selection. A wealth of experimental studies confirms a causal relationship between testosterone and reproductive behaviors (e.g., Schwabl and Kriner, 1991; Balthazart et al., 1995; Canoine and Gwinner, 2002; Sperry et al., 2010) and a mechanistic role for testosterone in the resolution of life history tradeoffs (e.g., Ketterson et al., 1992; Reed et al., 2006). However, only few studies have examined if individual variation in testosterone is correlated with reproductive success. Because of the known negative effects of testosterone on parental care and survival, selection on testosterone levels should vary with mating system, life history and life-cycle stage. Our study demonstrates that in a wild, socially monogamous song bird with male parental care, natural variation in testosterone can be positively related to variation in reproductive success, but the relationship depends on breeding stage. Our study thus suggests that selection may act differently on testosterone levels during different breeding phases. During the mating phase before the first brood, males gain most from aggressively defending their territory and mate, and thus selection on testosterone may be positive and directional. After the mating phase of the first brood, competing behaviors (parental care, extra-, and within-pair mating for the following brood) maximize the reproductive success of males and the optimal balance between these may depend strongly on current environmental conditions. Therefore, selection on testosterone levels may be harder to detect and/or may be non-directional during these later breeding phases. Furthermore, in comparison with the two other studies in socially monogamous species, our data indicate that a positive effect of testosterone on reproductive success may depend on the breeding behavior of the species, e.g., territorial vs. colonial. Detailed knowledge of when and how hormone levels relate to reproductive success is necessary to understand which selective 
pressures and environmental conditions have favored different endocrine phenotypes. Thus, our study contributes to a better understanding of hormone-mediated life history trade-offs in birds.

\section{AUTHOR CONTRIBUTIONS}

BA and WG conceived of and designed the study. BA coordinated the study, participated in fieldwork, carried out the statistical analyses, and drafted the manuscript; WG helped draft the manuscript; HF collected field data. All authors gave final approval for publication.

\section{REFERENCES}

Adkins-Regan, E. (2005). Hormones and Animal Social Behaviour. Princeton, NJ: Princeton University Press.

Alatalo, R. V., Hoglund, J., Lundberg, A., Rintamaki, P. T., and Silverin, B. (1996). Testosterone and male mating success on the black grouse leks. Proc. R. Soc. Biol. Sci. Ser. B 263, 1697-1702. doi: 10.1098/rspb.1996.0248

Apfelbeck, B., Mortega, K., Kiefer, S., Kipper, S., Vellema, M., Villavicencio, C. P., et al. (2013). Associated and disassociated patterns in hormones, song, behavior and brain receptor expression between life-cycle stages in male black redstarts, Phoenicurus ochruros. Gen. Comp. Endocrinol. 184, 93-102. doi: 10.1016/j.ygcen.2012.11.027

Apfelbeck, B., and Goymann W. (2011). Ignoring the challenge? Male black redstarts (Phoenicurus ochruros) do not increase testosterone levels during territorial conflicts but they do so in response to gonadotropinreleasing hormone. Proc. R. Soc. Biol. Sci. Ser. B 278, 3233-3242. doi: 10.1098/rspb.2011.0098

Ball, G. F., and Balthazart J. (2008). Individual variation and the endocrine regulation of behaviour and physiology in birds: a cellular/molecular perspective. Philos. Trans. R. Soc. Lond. B Biol. Sci. 363, 1699-1710. doi: 10.1098/rstb.2007.0010

Ball, G. F., Riters, L. V., and Balthazart, J. (2002). Neuroendocrinology of song behavior and avian brain plasticity: multiple sites of action of sex steroid hormones. Front. Neuroendocrinol. 23:230. doi: 10.1006/frne.2002.0230

Balthazart, J., Reid, J., Absil, P., Foidart, A., and Ball, G. F. (1995). Appetitive as well as consummatory aspects of male sexual-behavior in quail are activated by androgens and estrogens. Behav. Neurosci. 109, 485-501. doi: 10.1037/07357044.109.3.485

Baran, N. M., and Adkins-Regan, E. (2014). Breeding experience, alternative reproductive strategies and reproductive success in a captive colony of zebra finches (Taeniopygia guttata). PLoS ONE 9:e89808. doi: 10.1371/journal.pone.0089808

Beletsky, L. D., Orians, G. H., and Wingfield, J. C. (1992). Year-to-year patterns of circulating levels of testosterone and corticosterone in relation to breeding density, experience, and reproductive success of the polygynous red-winged blackbird. Horm. Behav. 26, 420-432. doi: 10.1016/0018-506X(92)90011-J

Birkhead, T. R., and Møller, A. P. (1993). Why do male birds stop copulating while their partners are still fertile? Anim. Behav. 45, 105-118.

Borgia, G., and Wingfield, J. C. (1991). Hormonal correlates of bower decoration and sexual display in the satin bowerbird (Ptilonorhynchus violaceus). Condor 93, 935-942. doi: 10.2307/3247728

Brooks, S. P., and Gelman, A. (1997). General methods for monitoring convergence of iterative simulations. J. Comput. Graph. Stat. 7, 434-455.

Canoine, V., and Gwinner, E. (2002). Seasonal differences in the hormonal control of territorial aggression in free-living European stonechats. Horm. Behav. 41, 1-8. doi: 10.1006/hbeh.2001.1720

Chandler, C. R., Ketterson, E. D., and Nolan, J. V. (1997). Effects of testosterone on use of space by male dark-eyed juncos when their mates are fertile. Anim. Behav. 54, 543-549. doi: 10.1006/anbe.1996.0448

Chandler, C. R., Ketterson, E. D., Nolan, V., and Ziegenfus, C. (1994). Effects of testosterone on spatial activity in free-ranging male dark-eyed

\section{FUNDING}

WG and field and laboratory work were supported by the Max-Planck-Gesellschaft. BA was supported by the MaxPlanck-Gesellschaft and the Alexander von Humboldt Stiftung.

\section{ACKNOWLEDGMENTS}

We thank Monika Trappschuh for assistance with the testosterone analysis and two referees for their constructive criticisms that helped to improve the manuscript.

juncos, Junco hyemalis. Anim. Behav. 47, 1445-1455. doi: 10.1006/anbe.1994 1191

Denwood, M. J. (2016). runjags: An R package providing interface utilities, parallel computing methods and additional distributions for MCMC models in JAGS. J. Stat. Softw. 71, 1-25. doi: 10.18637/jss.v071.i09

Eikenaar, C., Whitham, M., Komdeur, J., van der Velde, M., and Moore, I. T. (2011). Testosterone, plumage colouration and extra-pair paternity in male North-American barn swallows. PLoS ONE 6:e23288. doi: 10.1371/journal.pone.0023288

Flinks, H., and Pfeifer, F. (1987). Brutzeit, Gelegegröße und Bruterfolg beim Schwarzkehlchen (Saxicola torquata). Charadrius 23, 128-140.

Fusani, L. (2008). Testosterone control of male courtship in birds. Horm. Behav. 54, 227-233. doi: 10.1016/j.yhbeh.2008.04.004

Fusani, L., Beani, L., Lupo, C., and Dessi-Fulgheri, F. (1997). Sexually selected vigilance behaviour of the grey partridge is affected by plasma androgen levels. Anim. Behav. 54, 1013-1018. doi: 10.1006/anbe.1997.0518

Goymann, W., Villavicencio, C. P., and Apfelbeck, B. (2015). Does a shortterm increase in testosterone affect the intensity or persistence of territorial aggression? - An approach using an individual's hormonal reactive scope to study hormonal effects on behavior. Physiol. Behav. 149, 310-316. doi: 10.1016/j.physbeh.2015.06.029

Goymann, W., Geue, D., Schwabl, I., Flinks, H., Schmidl, D., Gwinner, H., et al. (2006). Testosterone and corticosterone during the breeding cycle of equatorial and European stonechats (Saxicola torquata axillaris and S. t. rubicola). Horm. Behav. 50, 779-785. doi: 10.1016/j.yhbeh.2006.07.002

Goymann, W., Schwabl, I., Trappschuh, M., and Hau, M. (2007). Use of ethanol for preserving steroid and indoleamine hormones in bird plasma. Gen. Comp. Endocrinol. 150, 191-195. doi: 10.1016/j.ygcen.2006.09.014

Greig-Smith, P. W. (1980). Parental investment in nest defense by stonechats (Saxicola torquata). Anim. Behav. 28, 604-619. doi: 10.1016/S0003-3472(80) 80069-8

Greig-Smith, P. W. (1982). Song-rates and parental care by individual male stonechats (Saxicola torquata). Anim. Behav. 30, 245-252. doi: 10.1016/S00033472(82)80261-3

Hegner, R. E., and Wingfield, J. C. (1987). Effects of experimental manipulation of testosterone levels on parental investment and breeding success in male house sparrows. Auk 104, 462-469. doi: 10.2307/4087545

Höglund, J., and Alatalo, R. V. (2014). Leks. Princeton, NJ: University Press.

Hunt, K. E., Hahn, T. P., and Wingfield, J. C. (1999). Endocrine influences on parental care during a short breeding season: testosterone and male parental care in Lapland longspurs (Calcarius lapponicus). Behav. Ecol. Sociobiol. 45, 360-369. doi: 10.1007/s002650050572

Jacobs, J. D., and Wingfield, J. C. (2000). Endocrine control of life-cycle stages: a constraint on response to the environment? Condor 102, 35-51. doi: $10.2307 / 1370406$

Ketterson, E. D., Nolan, V. Jr., Wolf, L., and Ziegenfus, C. (1992). Testosterone and avian life histories: effects of experimentally elevated testosterone on behavior and correlates of fitness in the dark-eyed junco (Junco hyemalis). Am. Nat. 140, 980-999. doi: 10.1086/285451

Ketterson, E. D., and Nolan, V. Jr. (1992). Hormones and life histories: an integrative approach. Am. Nat. 140, S33-S62. doi: 10.1086/285396 
Koenig, S., and Gwinner, E. (1995). Frequency and timing of successive broods in captive African and European stonechats Saxicola torquata axillaris and S. $t$. rubicola. J. Avian Biol. 26, 247-254. doi: 10.2307/3677326

Lynn, S. E. (2016). Endocrine and neuroendocrine regulation of fathering behavior in birds. Horm. Behav. 77, 237-248. doi: 10.1016/j.yhbeh.2015.04.005

Lynn, S. E., Walker, B. G., and Wingfield, J. C. (2005). A phylogenetically controlled test of hypotheses for behavioral insensitivity to testosterone in birds. Horm. Behav. 47, 170-177. doi: 10.1016/j.yhbeh.2004.10.004

Lynn, S. E., Hayward, L. S., Benowitz-Fredericks, Z. M., and Wingfield, J. C. (2002). Behavioural insensitivity to supplementary testosterone during the parental phase in the chestnut-collared longspur, Calcarius ornatus. Anim. Behav. 63, 795-803. doi: 10.1006/anbe.2001.1980

Mair, C., Stear, M., Johnson, P., Denwood, M., Jimenez de Cisneros, J. P., Stefan, T., et al. (2015). A bayesian generalized random regression model for estimating heritability using overdispersed count data. Genet. Selection Evol. 47, 1-13. doi: 10.1186/s12711-015-0125-5

Malo, A. F., Roldan, E. R., Garde, J. J., Soler, A. J., Vicente, J., Gomendio, C., et al. (2009). What does testosterone do for red deer males? Proc. Biol. Sci. 276, 971-980. doi: 10.1098/rspb.2008.1367

Marasco, V., Fusani, L., Dessì-Fulgheri, F., and Canoine, V. (2011). Nonmigratory stonechats show seasonal changes in the hormonal regulation of non-seasonal territorial aggression. Horm. Behav. 60, 414-419. doi: 10.1016/j.yhbeh.2011.07.010

Marler, C. A., and Moore, M. C. (1988). Evolutionary costs of aggression revealed by testosterone manipulations in free-living male lizards. Behav. Ecol. Sociobiol. 23, 21-26. doi: 10.1007/BF00303053

Marler, C. A., and Moore, M. C. (1989). Time and energy costs of aggression in testosterone-implanted free-living male mountain spiny lizards (Sceloporusjarrovi). Physiol. Zool. 62, 1334-1350. doi: 10.1086/physzool.62.6.30156216

McGlothlin, J. W., Jawor, J. M., and Ketterson, E. D. (2007). Natural variation in a testosterone mediated trade-off between mating effort and parental effort. Am. Nat. 170, 864-875. doi: 10.1086/522838

McGlothlin, J. W., Whittaker, D. J., Schrock, S. E., Gerlach, N. M., Jawor, J. M., Snajdr, E. A., et al. (2010). Natural selection on testosterone production in a wild songbird population. Am. Nat. 175, 687-701. doi: 10.1086/ 652469

Mills, S. C., Grapputo, A., Jokinen, I., Koskela, E., Mappes, T., Oksanen, T. A., et al. (2009). Testosterone - mediated effects on fitness - related phenotypic traits and fitness. Am. Nat. 173, 475-487. doi: 10.1086/597222

Mortega, K. G., Flinks, H., and Helm, B. (2014). Behavioural response of a migratory songbird to geographic variation in song and morphology. Front. Zool. 11:85. doi: 10.1186/s12983-014-0085-6

Nelson, R. J. (2005). An Introduction to Behavioral Endocrinology. Sunderland: Sinauer Associates, Inc. Publishers.

Peters, A. (2002). Testosterone and the trade-off between mating and paternal effort in extrapair-mating superb fairy-wrens. Anim. Behav. 64, 103-112. doi: 10.1006/anbe.2002.3037

Plummer, M. (2003). "JAGS: a program for analysis of bayesian graphical models using gibbs sampling," in Proceedings of the 3rd International Workshop on Distributed Statistical Computing (DSC 2003). Vienna.

Raouf, S. A., Parker, P. G., Ketterson, E. D., Nolan, V., and Ziegenfus, C. (1997). Testosterone affects reproductive success by influencing extra-pair fertilizations in male dark-eyed juncos (Aves: Junco hyemalis). Proc. Biol. Sci. 264, 1599-1603. doi: 10.1098/rspb.1997.0223

R Core Team (2016). R: A Language and Environment for Statistical Computing. Vienna: R Foundation for Statistical Computing.

Reed, W. L., Clark, M. E., Parker, P. G., Raouf, S. A., Arguedas, N., Monk, D. S., et al. (2006). Physiological effects on demography: a long-term experimental study of testosterone's effects on fitness. Am. Nat. 167, 667-683. doi: 10.1086/503054

Rosvall, K. A., Bergeon Burns, C. M., Barske, J., Goodson, J. L., Schlinger, B. A., Sengelaub, D. R., et al. (2012). Neural sensitivity to sex steroids predicts individual differences in aggression: implications for behavioural evolution. Proc. Biol. Sci. 279, 3547-3555. doi: 10.1098/rspb.2012.0442

Safran, R. J., Adelman, J. S., McGraw, K. J., and Hau, M. (2008). Sexual signal exaggeration affects physiological state in male barn swallows. Curr. Biol. 18, R461-R462. doi: 10.1016/j.cub.2008.03.031

Scheuerlein, A., Van't Hof, T., and Gwinner, E. (2001). Predators as stressors? Physiological and reproductive consequences of predation risk in tropical stonechats (Saxicola torquata axillaris). Proc. Biol. Sci. 268, 1575-1582. doi: 10.1098/rspb.2001.1691

Schwabl, H., and Kriner, E. (1991). Territorial aggression and song of male European robins (Erithacus rubecula) in autumn and spring: effects of antiandrogen treatment. Horm. Behav. 25, 180-194. doi: 10.1016/0018506X(91)90049-N

Schwabl, H., Flinks, H., and Gwinner, E. (2005). Testosterone, reproductive stage, and territorial behavior of male and female European stonechats Saxicola torquata. Horm. Behav. 47, 503-512. doi: 10.1016/j.yhbeh.2004.08.003

Schwagmeyer, P. L., Schwabl, H. G., and Mock, D. W. (2005). Dynamics of biparental care in house sparrows: hormonal manipulations of paternal contributions. Anim. Behav. 69, 481-488. doi: 10.1016/j.anbehav.2004.04.017

Silverin, B. (1980). Effects of long-acting testosterone treatment on freeliving pied flycatchers, Ficedula hypoleuca, during the breeding period. Anim. Behav. 28, 906-912. doi: 10.1016/S0003-3472(80)80152-7

Smith, C. F., Schuett, G. W., and Amarello, M. (2015). Male mating success in a North American pitviper: influence of body size, testosterone, and spatial metrics. Biol. J. Linn. Soc. 115, 185-194. doi: 10.1111/bij.12490

Sperry, T. S., Wacker, D. W., and Wingfield, J. C. (2010). The role of androgen receptors in regulating territorial aggression in male song sparrows. Horm. Behav. 57, 86-95. doi: 10.1016/j.yhbeh.2009.09.015

Urquhart, E. D. (2002). Stonechats. London: Christopher Helm.

Van de Crommenacker, J., Richardson, D. S., Groothuis, T. G. G., Eising, C. M., Dekker, A. L., and Komdeur, J. (2004). Testosterone, cuckoldry risk and extrapair opportunities in the Seychelles warbler. Proc. Biol. Sci. 271, 1023-1031. doi: 10.1098/rspb.2004.2697

Van Duyse, E., Pinxten, R., and Eens, M. (2000). Does testosterone affect the tradeoff between investment in sexual/territorial behaviour and parental care in male great tits? Behaviour 137, 1503-1515. doi: 10.1163/156853900502691

Villavicencio, C., Apfelbeck, B., and Goymann, W. (2014). Parental care, loss of paternity and circulating levels of testosterone and corticosterone in a socially monogamous song bird. Front. Zool. 11:11. doi: 10.1186/1742-9994-11-11

Vitousek, M. N., Rubenstein, D. R., Nelson, K. N., and Wikelski, M. (2008). Are hotshots always hot? A longitudinal study of hormones, behavior, and reproductive success in male marine iguanas. Gen. Comp. Endocrinol. 157, 227-232. doi: 10.1016/j.ygcen.2008.04.015

Weggler, M. (2006). Constraints on, and determinants of, the annual number of breeding attempts in the multi-brooded black redstart, Phoenicurus ochruros. Ibis 148, 273-284. doi: 10.1111/j.1474-919X.2006.00527.x

Wingfield, J. C. (2005). A continuing saga: the role of testosterone in aggression. Horm. Behav. 48, 253-255. doi: 10.1016/j.yhbeh.2005.05.009

Wingfield, J. C., Moore, I. T., Goymann, W., Wacker, D. W., and Sperry, T. S. (2006). "Contexts and ethology of vertebrate aggression: implications for the evolution of hormone-behavior interactions," in Biology of Aggression, ed R. J. Nelson (New York, NY: Oxford University Press Inc.), 179-210.

Wingfield, J. C., Hegner, R. E., Dufty, A. M. Jr., and Ball, G. F. (1990). The challenge hypothesis: Theoretical implications for patterns of testosterone secretion, mating systems, and breeding strategies. Am. Nat. 136, 829-846. doi: $10.1086 / 285134$

Wingfield, J. C., Lynn, S., and Soma, K. K. (2001). Avoiding the costs of testosterone: ecological bases of hormone-behavior interactions. Brain Behav. Evol. 57, 239. doi: 10.1159/000047243

Wingfield, J. C., and Hahn, T. P. (1994). Testosterone and territorial behaviour in sedentary and migratory sparrows. Anim. Behav. 47, 77-89. doi: 10.1006/anbe.1994.1009

Yang, C., Wang, J., Fang, Y., and Sun, Y.-H. (2013). Is sexual ornamentation an honest signal of male quality in the Chinese grouse (Tetrastes sewerzowi)? PLoS ONE 8:e82972. doi: 10.1371/journal.pone.0082972

Conflict of Interest Statement: The authors declare that the research was conducted in the absence of any commercial or financial relationships that could be construed as a potential conflict of interest.

Copyright (๑ 2016 Apfelbeck, Flinks and Goymann. This is an open-access article distributed under the terms of the Creative Commons Attribution License (CC BY). The use, distribution or reproduction in other forums is permitted, provided the original author(s) or licensor are credited and that the original publication in this journal is cited, in accordance with accepted academic practice. No use, distribution or reproduction is permitted which does not comply with these terms. 